\title{
Bazı Entomopatojen Fungusların Baklazınnı, Epicometis hirta (Poda) (Coleoptera: Scarabaeidae) Erginlerine Karşı Virülensliği ${ }^{*}$
}

\author{
Sevim ATMACA ${ }^{1}$, Gamze PEKBEY ${ }^{1}$, Ramazan CANHILAL ${ }^{2}$
}

ÖZET: Baklazınnı, Epicometis hirta (Poda) (Coleoptera: Scarabaeidae), elma üretimini sınırlandıran önemli bir zararlıdır. Bu çalışma, Adana ve civarından alınan topraklardan izole edilen iki entomopatojen fungusun (Beauveria bassiana ve Fusarium sp.) etkinliğini incelemek amacıyla yapılmıştır. Yozgat ili Sorgun ilçesi Gedikhasanlı köyünden $E$. hirta erginleri toplanmış ve püskürtme yöntemi ile $1 \times 10^{6}, 1 \times 10^{7}$ ve $1 \times 10^{8}$ konidi $\mathrm{ml}^{-1}$ dozlarında entomopatojen funguslar zararlıya inoküle edilmiştir. Dört tekerrürlü kurulan denemede konsantrasyon başına (her tekerrürde) 10 ergin ve toplamda 40 ergin kullanılmıştır. İnokülasyondan sonra 7. ve 14. günde ölüm oranları ve mikozis değerleri hesaplanmıştır. Yedinci günde mortalite oranları sırasıyla; B. bassiana için $\% 60, \% 85, \% 80$ ve Fusarium sp. izolatlatı için $\% 40, \% 35, \% 40$ olarak hesaplanmıştır. On dördüncü günde mortalite oranları sırasıyla; B. bassiana için $\% 70, \% 90, \% 90$ ve Fusarium sp. izolatlatı için $\% 50, \% 70, \% 75$ olarak hesaplanmıştır. $\mathrm{LC}_{50}$ değerleri Fusarium sp. (213) ve B. bassiana (310) izolatları sırasıly $251.83 \times 10^{5}$ ve $101.94 \times 10^{5}$ konidi ergin $^{-1}$ olarak bulunmuştur. Çalışmanın sonucunda $B$. bassiana izolatının $\left(1 \times 10^{7}\right.$ ve $1 \times 10^{8}$ konidi $\mathrm{ml}^{-1}$ dozları) zararlıyı yönetmeye yönelik biyolojik mücadele programlarında potansiyel biyolojik kontrol ajanı olarak kullanılabilir olduğunu göstermiştir.

Anahtar Kelimeler: Beauveria bassiana, entomopatojen fungus, Epicometis hirta, Fusarium sp.

\section{Virulence of Some Entomopathogenic Fungi Against Adult of Blossom Beetle, Epicometis hirta (Poda) (Coleoptera: Scarabaeidae)}

\begin{abstract}
ABSRACT: The Blossom Beetle Epicometis hirta (Poda) (Coleoptera: Scarabaeidae) is one of the important pest that limits apple production.. This study was aimed to examine the role of two entomopathogenic fungi (Beauveria bassiana and Fusarium sp.) were isolated from field soil from Adana province. E. hirta collected from Yozgat, Sorgun, Gedikhasanlı province and the districts and the entomopathogenic fungi inoculated on E. hirta adults by spraying method. In the experiment, $1 \times 10^{6}, 1 \times 10^{7}$ and $1 \times 10^{8}$ conidia $\mathrm{ml}^{-1}$ concentrations were used. 40 adults per concentration and 10 adults per recurrence were used within four recurrences. After the inoculation, mortality rates mycosis rate and were calculated for day 7 and 14 days. At 7th day, the mortality rates of B. bassiana were calculated as, $60 \%, 85 \%, 80 \%$ and for Fusarium sp. isolates were calculated as; $40 \%, 35 \%, 40 \%$ respectively. At 14th day, the mortality rates of $B$. bassiana were calculated as 70\%, 90\%, 90\% and for Fusarium sp. isolates; $50 \%$, $70 \%, 75 \%$ respectively. $\mathrm{LC}_{50}$ values were determined using Fusarium sp. (213) and B. bassiana (310) isolates were $251.83 \times 10^{5}$ and $101.94 \times 10^{5}$ conidia mature ${ }^{-1}$, respectively. The results of the study $B$. bassiana isolates $\left(1 \times 10^{7}\right.$ and $1 \times 10^{8}$ conidia $\mathrm{ml}^{-1}$ doses) could be used as potential biological control agents in classical biological control programs aimed at managing the pest.
\end{abstract}

Keywords: Beauveria bassiana, entomopathogenic fungi, Epicometis hirta, Fusarium sp.

Sevim ATMACA (0000-0001-8568-3469), Gamze PEKBEY (0000-0002-0314-0071), Bozok Üniversitesi, Ziraat Fakültesi, Bitki Koruma Bölümü, Yozgat, Türkiye

Ramazan CANHILAL (0000-0002-5374-5458), Erciyes Üniversitesi, Ziraat Fakültesi, Bitki Koruma Bölümü, Kayseri, Türkiye Sorumlu yazar/Corresponding Author: Sevim ATMACA, sevim.dogan@bozok.edu.tr

Bu çalışma 14-16 Eylül 2017 tarihinde Tokat-Türkiye'de düzenlenen 6th Enthomopathogens and Microbial Control Congress'inda sunulmuş ve kongre özet kitabında yayınlanmışır. 


\section{GİRIŞ}

Epicometis hirta (Poda) (Coleoptera: Scarabaeidae) erginleri meyve ağaçları ve diğer bitkilerin çiçek açma zamanında, çiçek organlarının polen tozlarını, genç yaprakları, tomurcuk ve meyveleri yiyerek zararlı olurlar (Anonim, 2008). Bunun sonucu olarak zarar görmüş çiçekler meyve bağlayamaz ve verimde azalma, ürün kalitesinde farklılık gözlemlenir (Özbek, 2008). Konukçuları arasında başta elma olmak üzere, armut, kiraz, kayısı gibi meyve ağaçları, buğdaygiller, süs bitkileri ve bazı yabancı otlar bulunmaktadır.

Zararlı ile mekanik, biyoteknik, kültürel ve kimyasal mücadele yapılmaktadır. Ülkemizde $E$. hirta'ya karşı ruhsatlı ilaç bulunmaması bu zararlı ile mücadeleyi zorlaştırmaktadır. Uygulanan biyoteknik ve kültürel mücadele yöntemleri doğru uygulanmadığ 1 takdirde mücadeleyi başarısız kılmaktadır. Kimyasal mücadele bal arılarının ölümüne ve ağaçlarda çiçek, tomurcuk dökümüne sebep olmasından ötürü tavsiye edilmemektedir.

Yapılan çalışmalarda önemli yer tutan yöntemlerden biri, biyolojik mücadele yöntemidir. Entomopatojen funguslar da biyolojik mücadelede kullanılan önemli etmenlerin başında gelmektedir. Entomopatojen funguslar, böceklerin vücutlarında hastalık oluşturmak suretiyle ölümlerine sebep olmaktadır. Yapılan literatür taramalarında ülkemizde daha önce $E$. hirta'ya karşı, entomopatojen fungusların mücadele ajanı olarak kullanılmadığı görülmektedir. Son zamanlarda yapılan çalışmalarda, zararlının dahil olduğu taksonomik gruba (Coleoptera: Scarabaeidae) karşı entomopatojen fungusların etkileri araştırılmıştır (Ansari et al., 2006; Nong et al., 2011; Erler and Ates, 2015; Khanal, 2016; Kheswa et al., 2016).

$\mathrm{Bu}$ çalışma ile yerel entomopatojen fungus izolatlarının yöremizde ekonomik zararlı olan baklazınnı erginlerine karşı laboratuvar ortamında virülensliği test edilmiştir.

\section{MATERYALVE YÖNTEM}

\section{Epicometis hirta'nın Erginlerinin Elde Edilmesi}

Yozgat İli Sorgun İlçesi Gedikhasanlı Köyü’ünde bulunan Ziraat Fakültesi araştırma arazisine gidilerek, elma, armut, kiraz ağaçlarının çiçeklenme döneminde, 27 Nisan 2017 tarihinde sürvey yapılmıştır (Şekil 1). Çalışma için yeterli miktarda E. hirta erginleri bitkilerden elle toplanarak, numune kaplarına konulmuştur. Beslenmeleri için kapların içine elma çiçekleri konularak kapların üzeri havayı geçiren tül ile kapatılmıştır. Laboratuvara getirilen erginler, deneme desenine göre petrilere aktarılmıştır. (Şekil 2).

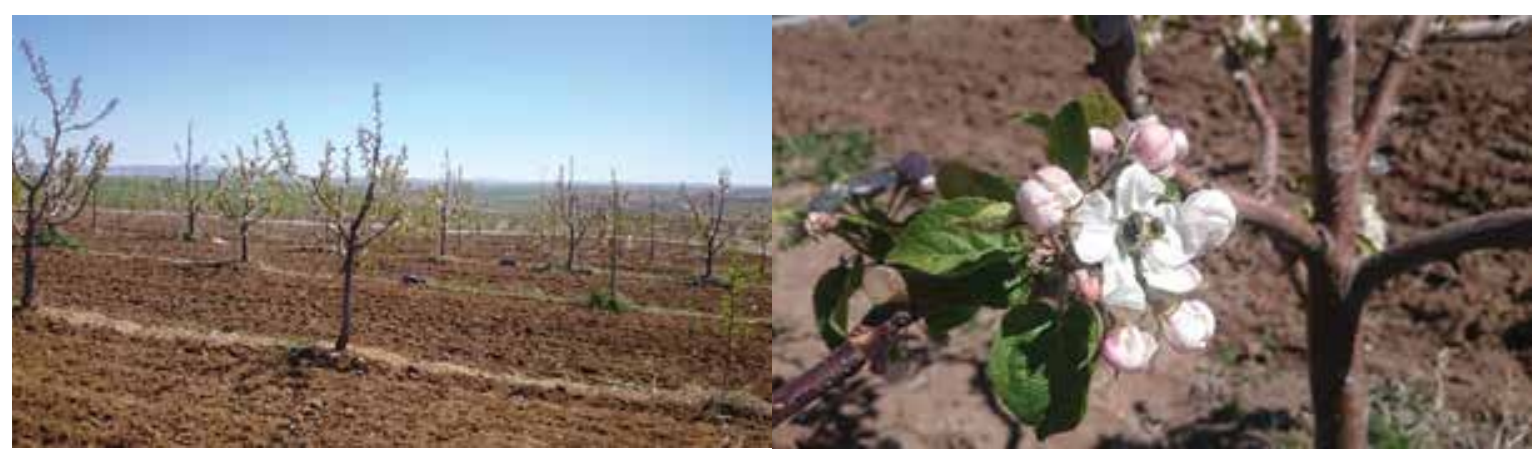

Şekil 1. Araştırma alanı genel görünüm

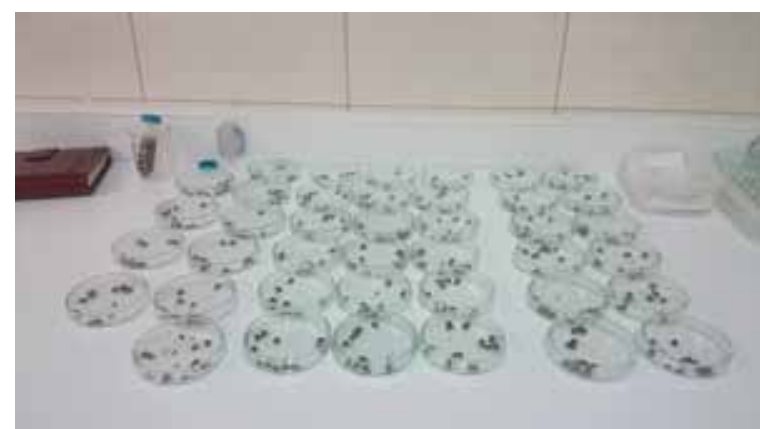

a)

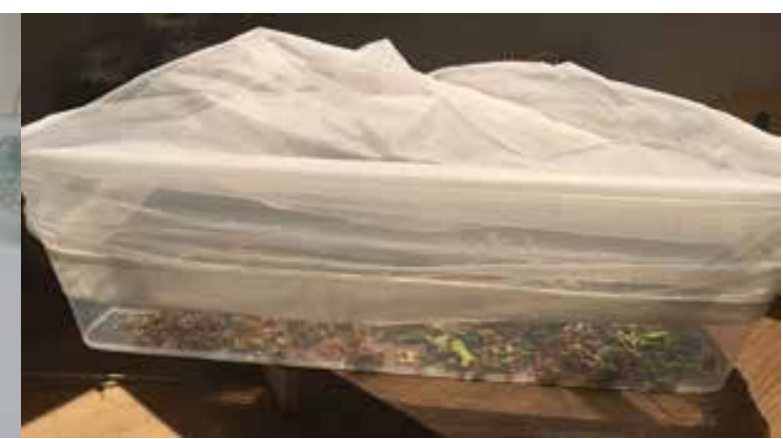

b)

Şekil 2. a) Araziden toplanan ergin böcekler, b) Erginlerin petrilere aktarılması 


\section{Entomopatojen Fungusların Elde Edilmesi}

Entomopatojen fungus (EPF)'lar Erciyes Üniversitesi, Ziraat Fakültesi, Bitki Koruma Bölüm Laboratuvarı'ndan temin edilmiştir. Daha önce yürütülen bir proje kapsamında Adana ve civarındaki araziler Eylül-Ekim-Kasım ve Mart-Nisan-Mayıs aylarında gezilerek topraktan izolasyon yapılmışırı (Atmaca, 2016). Kültüre alınan entomopatojen funguslara kodlar verilmiştir (B. bassiana (310), Fusarium sp. (213)).

\section{Biyolojik Etkinliklerinin Belirlenmesi}

Denemelerde, B. bassiana ve Fusarium sp. entomopatojen fungusları kullanılmıştır. Mevcut kültürler, içerisinde Potato Dextrose Agar (PDA) (Merck) ortamı bulunan $90 \mathrm{~mm}$ çaplı steril petri kaplarına ekilmiş ve $25 \pm 1^{\circ} \mathrm{C}$ ' de 14 gün boyunca geliştirilmiştir. Spor sayısı, mikroskopta Thoma lamında say1lip, $1 \mathrm{ml} \% 0.01$ Tween- 20 solüsyonunda $1 \times 10^{6}, 1 \times 10^{7}$ ve $1 \times 10^{8}$ konidi olacak şekilde ayarlanmıştır. Kontrolde ise $\% 0.01$ Tween-20 solüsyonu kullanılmıştır. Belirlenen dozlar, içinde kurutma kağıdı bulunan $9 \mathrm{~cm}$ 'lik cam petri kaplarında bulunan E. hirta erginlerine $1 \mathrm{ml}$ dozunda sprey inokule yöntemiyle uygulanmıştır (Atmaca, 2016). Denemeler 4 tekerrürlü ve her tekerrürde 10 ergin birey olacak şekilde gerçekleştirilmiş olup, petriler $27 \pm 2^{\circ} \mathrm{C}^{\prime}$ deki inkübatöre konulmuştur.

İnkübasyon süresince $E$. hirta'nın erginlerinin beslenmesi için her petri kabına, araziden toplanan elma ağacı yaprak ve çiçekleri konulmuştur (Şekil 3). Yürütülen denemede sayımlar 7 ve 14 . günde yapılarak kayıt altına alınmıştır. Ölü erginler \%1'lik sodyum hipoklorit çözeltisiyle yüzey sterilizasyonu yapıldıktan sonra steril nemli filtre kağıdı içeren petrilere konulmuştur, mikozis gözlenen bireyler kaydedilmiştir (Şekil 4).
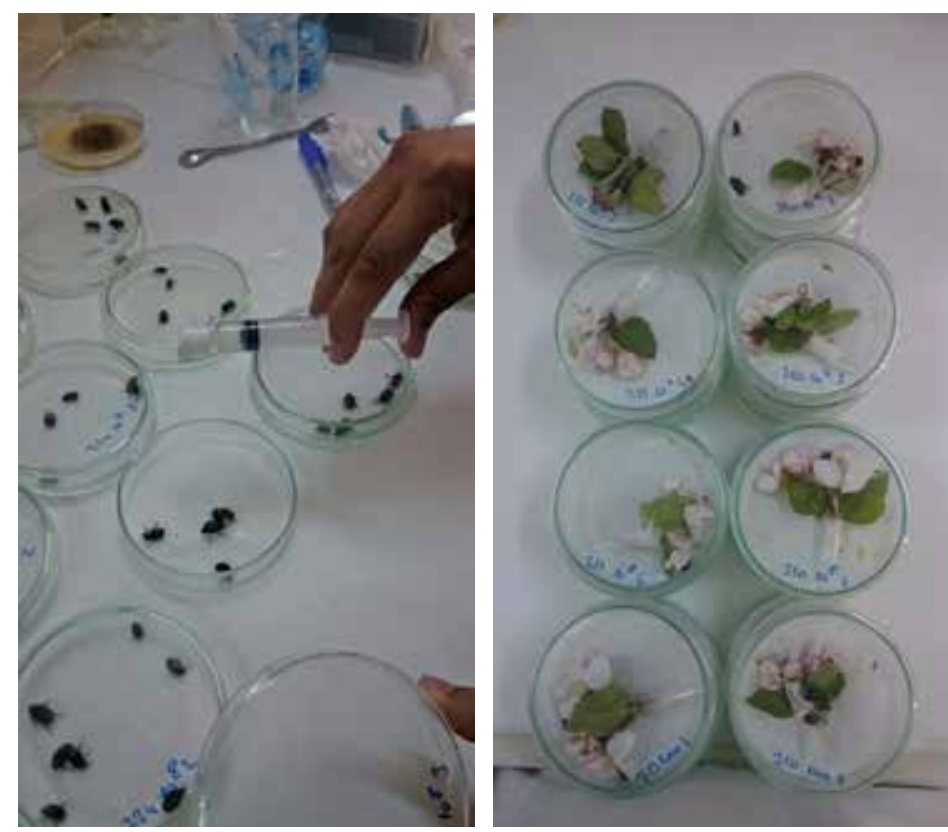

Şekil 3. Sprey inokule yöntemi ve içlerinde besin bulunan petri kapları
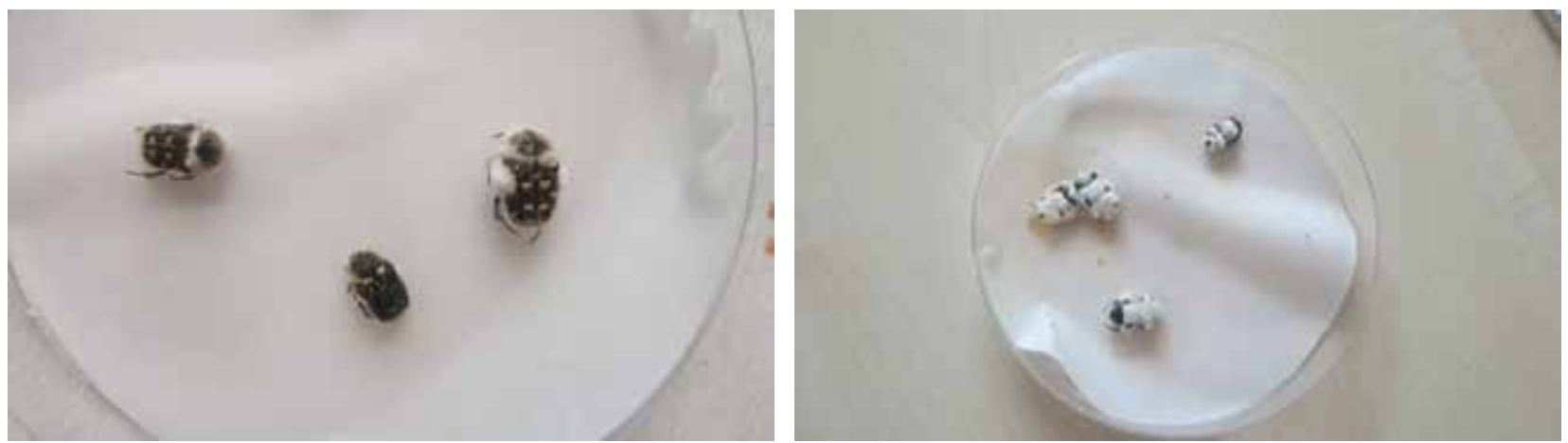

Şekil 4. Mikozis gelişimi gösteren ölü bireyler 


\section{Veri Analizleri}

EPF'ların yüzde ölüm oranları Abbott'un (1925) formülü ile kontrole göre düzenlenmiştir. Fungusların $E$. hirta üzerinde oluşturduğu ölüm oranları arasındaki farkların karşılaştııılmasında, SPSS 20.0 istatistik programı kullanılarak ANOVA uygulanmış ve Duncan testi kullanılmıştır. Letal konsatrasyon $\left(\mathrm{LC}_{50}\right)$ değerleri probit analizi ile hesaplanmıştır (SPSS, 2003).

\section{BULGULAR VE TARTIŞMA}

Ölen ve mikozis oluşan E. hirta erginlerinin oluşturduğu ortalama \% ölüm oranları ve Letal konsatrasyon $\left(\mathrm{LC}_{50}\right)$ değerleri hesaplanmıştır (Çizelge 1, Çizelge 2 ve Çizelge 3).

Çizelge 1. Beauveria bassiana ve Fusarium sp.'nin Epicometis hirta üzerine 7. günde farklı dozlarda oluşturduğu ortalama \% ölüm oranları

\begin{tabular}{lcccc}
\hline \multirow{2}{*}{$\begin{array}{l}\text { Entomopatojen } \\
\text { Fungus }\end{array}$} & İzolat No & \multicolumn{3}{c}{ Ortalama \% ölüm oranları } \\
\cline { 3 - 5 } & & $\mathbf{1 x 1 0}^{\mathbf{6}}$ & $\mathbf{1 \times 1 \mathbf { 1 0 } ^ { 7 }}$ & $\mathbf{1 x 1 0}^{\mathbf{8}}$ \\
\hline Beauveria bassiana & 310 & $60.000 \mathrm{ab}^{*}$ & $85.000 \mathrm{a}$ & $80.000 \mathrm{ab}$ \\
Fusarium sp. & 213 & $40.000 \mathrm{abc}$ & $35.000 \mathrm{bc}$ & $40.000 \mathrm{abc}$ \\
Kontrol & - & $10.000 \mathrm{c}$ & $10.000 \mathrm{c}$ & $10.000 \mathrm{c}$ \\
\hline
\end{tabular}

* Aynı harfi içeren ortalamalar arasında istatistikî olarak önemli bir fark yoktur $(\mathrm{P}<0.05)$

Yedinci günde $1 \times 10^{6}$ konidi $\mathrm{ml}^{-1}$ dozunda, $B$. bassiana ve Fusarium sp. izolatlarının ölüm oranları sırasıyla, $\% 60, \% 40$ olarak bulunmuş ve istatistiki açıdan aynı grupta yer almıştır. $1 \times 10^{7}$ konidi $\mathrm{ml}^{-1}$ dozunda elde edilen değerler incelendiğinde, $B$. bassiana ve
Fusarium sp. izolatlarının ölüm oranları sırasıyla; \%85 ve $\% 35$ olarak bulunmuştur. $1 \times 10^{8}$ konidi $\mathrm{ml}^{-1}$ dozunda, B. bassiana izolatının oluşturduğu ölüm oranı $(\% 80)$ ve Fusarium sp. izolatının oluşturduğu ölüm oranı (\%40) istatistiki olarak aynı grupta yer almıştır.

Çizelge 2. Beauveria bassiana ve Fusarium sp.'nin Epicometis hirta üzerine 14. günde farklı dozlarda oluşturduğu ortalama \% ölüm oranları

\begin{tabular}{lcccc}
\hline \multirow{2}{*}{$\begin{array}{l}\text { Entomopatojen } \\
\text { Fungus }\end{array}$} & İzolat No & \multicolumn{3}{c}{ Ortalama \% ölüm oranları } \\
\cline { 3 - 5 } & & $\mathbf{1 x 1 0}^{\mathbf{6}}$ & $\mathbf{1 x 1 \mathbf { 0 } ^ { 7 }}$ & $\mathbf{1 x 1 0}^{\mathbf{8}}$ \\
\hline Beauveria bassiana & 310 & $70.000 \mathrm{a}^{*}$ & $90.000 \mathrm{a}$ & $90.000 \mathrm{a}$ \\
Fusarium $\mathrm{sp}$ s & 213 & $50.000 \mathrm{ab}$ & $70.000 \mathrm{a}$ & $75.000 \mathrm{a}$ \\
Control & - & $10.000 \mathrm{~b}$ & $10.000 \mathrm{~b}$ & $10.000 \mathrm{~b}$ \\
\hline
\end{tabular}

*Aynı harfi içeren ortalamalar arasında istatistikî olarak önemli bir fark yoktur $(\mathrm{P}<0.05)$

İzolatların oluşturdukları ölüm oranları istatistiki açıdan birbirlerinden farklı bulunmamıştır. Sayısal değer olarak en yüksek ölüm oranı $B$. bassiana izolatının $1 \times 10^{7}$ konidi $\mathrm{ml}^{-1}$ ve $1 \times 10^{8}$ konidi $\mathrm{ml}^{-1}$ dozlarında hesaplanmıştır (Çizelge 2).

Yapılan bu çalışma önceki yapılan çalışmalarla karşılaştırıldı ğında; Polyphylla fullo (Linnaeus) (Coleoptera: Scarabaeidae)'ya karşı biyolojik

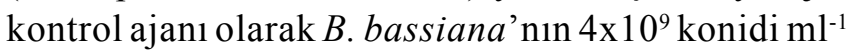
dozu genç ve yaşlı larvalarda sırasıyla \%79.8 ve \%71.6'ya kadar ölümler oluşturmuştur.
Çalışmada kullanılan doz $\left(4 \times 10^{9}\right.$ konidi $\left.\mathrm{ml}^{-1}\right)$ bu çalışmadaki dozlardan fazla olmasına rağmen ölüm oranları benzerlik göstermektedir (Erler and Ates, 2015).

Kheswa et al., (2016) yaptıkları çalışmada; iki Beauveria brongniartii izolatını Scarabaeidae (Coleoptera) familyasındaki bazı türlere, $1 \times 10^{9}$ konidi $\mathrm{ml}^{-1}$ lik konsantrasyonda denemiş ve larvalar üzerindeki ölüm oranını, \%80-90 olarak tespit etmişlerdir. $\mathrm{Bu}$ çalışmadaki sonuçlarla (\%75-90) hemen hemen benzerdir. 
Çizelge 3. Beauveria bassiana ve Fusarium sp. izolatlarının $\mathrm{LC}_{50}$ değerleri

\begin{tabular}{lcccc}
\hline $\begin{array}{l}\text { Entomopatojen } \\
\text { Fungus }\end{array}$ & İzolat No & $\mathbf{L C}_{\mathbf{5 0}}(\mathbf{x 1 0})$ & $\mathbf{X}^{\mathbf{5}}$ & $\mathbf{P}$ \\
\hline B.bassiana & 310 & 101.940 & 57.960 & 0.0001 \\
Fusarium sp. & 213 & 251.830 & 63.580 & 0.0001 \\
\hline
\end{tabular}

$\mathrm{Bu}$ çalışmadaki, $\mathrm{LC}_{50}$ değerleri, Fusarium. sp. ve $B$. bassiana izolatları için surasıyla, $251.83 \times 10^{5}$ ve $101.94 \times 10^{5}$ konidi ergin ${ }^{-1}$ olarak hesaplanmıştır. $\mathrm{Bu}$ değerler, ölüm oranları ile paralellik göstermektedir.

Nong et al., (2011) yaptıkları çalışmada; $B$. bassiana'nın Holotrichia oblita (Faldermann) ve Anomala corpulenta (Motschulsky)'nın (Coleoptera: Scarabaeidae) üzerinde oluşturduğu $\mathrm{LC}_{50}$ değerini 4.49 $\times 10^{6}$ konidi $\mathrm{ml}^{-1}$ olarak belirtmişlerdir. Çalışmada kullanılan izolatın $\mathrm{LC}_{50}$ değeri bu değerden daha yüksek bulunmuştur.

\section{SONUÇ}

$\mathrm{Bu}$ çalışma ile daha önce hiç çalışma yapılmayan E. hirta'nın alternatif mücadelesinde kullanılabilecek entomopatojen fungus türlerinin öldürücü etkileri belirlenmiştir. Yapılan analizler sonucunda, Fusarium sp. (213) ve $B$. bassiana (310) izolatları $1 \times 10^{8}$ konidi $\mathrm{ml}^{-1}$ dozunda istatistiki olarak birbirine yakın sonuçlar vererek, E. hirta için virülens izolatlar olarak tespit edilmiștir. Scarabaeidae familyasındaki bazı türlere karşı yapılan önceki çalışmalarda, B. bassiana izolatı en virülens bulunurken, bu çalışmada, Fusarium sp. izolatının da $B$. bassiana kadar virülens olduğu belirlenmiştir.

\section{KAYNAKLAR}

Abbott WS, 1925. A method of computing the effectiveness of an insecticide. Journal of Economic Entomology, 18: 265-267.

Anonim, 2008. Zirai Mücadele Teknik Talimatları. Cilt 4, Ankara, TÜRKIYE. $129 \mathrm{~s}$.

Ansari MA, Shah FA, Tirry L, Moens M, 2006. Field trials against Hoplia philanthus (Coleoptera: Scarabaeidae) with a combination of an entomopathogenic nematode and the fungus Metarhizium anisopliae CLO 53. Biological Control, 39:453-459.
$\mathrm{Bu}$ çalışma, entomopatojen fungusların potansiyel olarak E. hirta erginlerine karşı kullanılması için bir ön çalışma niteliğindedir. Etkili bulunan Fusarium sp. (213) ve $B$. bassiana (310) izolatlarının, elma zararlıları ve diğer zararlılara karşı kullanılabilirliğinin araştırılması gereklidir. Tarla denemeleri için $B$. bassiana (310) izolatının $1 \times 10^{7}$ konidi $\mathrm{ml}^{-1}$ ve $1 \times 10^{8}$ konidi $\mathrm{ml}^{-1}$ dozlarının denebileceği kanaatine varılmıştır. Gelecekteki çalışmalarla, entomopatojen fungusların etki süresinin kısaltılması, daha spesifikleştirilmesi, raf ömrünün uzatılabilmesi gibi konularda kaydedilecek ilerlemeler ve diğer mücadele teknikleri ile sinerji oluşturulması, entomopatojen fungusların kullanılabilirliğini artıracaktır.

\section{TEŞEKKÜR}

$\mathrm{Bu}$ çalışmamızı 6602b-ZF/16-20 nolu proje ile destekleyen, Bozok Üniversitesi Bilimsel Araştırma Projeler (BAP) Birimi Koordinatörlüğ̈̈’ne teşekkür ederiz.

Bu çalışmanın özeti, yazarlar tarafından 14-16 Eylül 2017 tarihlerinde Tokat'ta yapilan ' $6^{\text {th }}$ International Participated Enthomopathogens and Microbial Control Symposium' da (Poster, s. 79) sunulmuştur.

Atmaca S, 2016. Adana topraklarından entomopatojen fungusların izolasyonu, morfolojik karakterizasyonu ve Sitophilus oryzae erginlerine karşı laboratuvar şartlarında virülensliklerinin belirlenmesi. Erciyes Üniversitesi Fen Bilimleri Enstitüsü, Yüksek Lisans Tezi, 77s.

Erler F, Ates AO, 2015. Potential of two entomopathogenic fungi, Beauveria bassiana and Metarhizium anisopliae (Coleoptera: Scarabaeidae), as biological control agents against the June beetle. J. Insect Sci, 15(1): 44; DOI: 10.1093/jisesa/iev029.

Khanal D, 2016. Activity of strains of Metarhizium anisopliae (Metsch) Sorokin against white grub (Chiloloba acuta, 
Sevim ATMACA ve Ark.

Scarabaeidae, Coleoptera) under laboratory condition in Nepal. The Journal of Agriculture and Environment, Vol:17.

Kheswa N, Laing M, Conlong DE, 2016. Evaluation of two Beauveria brongniartii isolates for pathogenicity against different life stages of white grub species (Coleoptera: Scarabaeidae) in south african sugarcane. Proc S Afr Sug Technol Ass, (2016) 89: 98-115.

Nong X, Liu C, Lu X, Wang Q, Wang G, Zhang Z, 2011. Laboratory evaluation of entomopathogenic fungi against the White grubs, Holotrichia oblita and Anomala corpulenta (Coleoptera: Scarabaeidae) from the field of peanut, Arachis hypogaea. Biocontrol Science and Technology, Vol. 21, No. 5, 2011, 593-603.
Özbek H, 2008. Türkiye'de 1lıman iklim meyve türlerini ziyaret eden böcek türleri. Uludağ Arıcılık Dergisi, 8 (3): 92-103.

SPSS, 2003. A simple Guide and Reference, 11.0 Update. Pearson Education Inc., Boston.

Yaşar B, Çeşme İ, Baydar MS, Aysal İ, Yazır AB, 2013. Farklı mavi renkli huni tuzaklarının kiraz ağaçları çiçeklerinde beslenen baklazınnı [Epicometis hirta (Poda) (Coleoptera: Scarabaeidae)]'nın yakalanması üzerine etkisi. Türk. entomol. bült., 3 (2): 99-105. 